\title{
Light-distortion analysis as a possible indicator of visual quality after refractive lens exchange with diffractive multifocal intraocular lenses
}

\author{
Pedro Brito, MD, José Salgado-Borges, MD, PhD, Helena Neves, MSc, José Gonzalez-Meijome, PhD, \\ Manuel Monteiro, MD, PhD
}

PURPOSE: To study the perception of light distortion after refractive lens exchange (RLE) with diffractive multifocal intraocular lenses (IOLS).

SETTING: Clínica Oftalmológica das Antas, Porto, Portugal.

DESIGN: Retrospective comparative study.

METHODS: Refractive lens exchange was performed with implantation of an AT Lisa 839M (trifocal) or 909MP (bifocal toric) IOL, the latter if corneal astigmatism was more than 0.75 diopter (D). The postoperative visual and refractive outcomes were evaluated. A prototype light-distortion analyzer was used to quantify the postoperative light-distortion indices. A control group of eyes in which a Tecnis ZCBOO 1-piece monofocal IOL was implanted had the same examinations.

RESULTS: A trifocal or bifocal toric IOL was implanted in 66 eyes. The control IOL was implanted in 18 eyes. All 3 groups obtained a significant improvement in uncorrected distance visual acuity (UDVA) $(P<.001)$ and corrected distance visual acuity (CDVA) $(P=.001)$. The mean uncorrected near visual acuity (UNVA) was $0.123 \log M A R$ with the trifocal IOL and $0.130 \log M A R$ with the bifocal toric IOL. The residual refractive cylinder was less than $1.00 \mathrm{D}$ in $86.7 \%$ of cases with the toric IOL. The mean light-distortion index was significantly higher in the multifocal IOL groups than in the monofocal group $(P<.001)$, although no correlation was found between the light-distortion index and CDVA.

CONCLUSIONS: The multifocal IOLs provided excellent UDVA and functional UNVA despite increased light-distortion indices. The light-distortion analyzer reliably quantified a subjective component of vision distinct from visual acuity; it may become a useful adjunct in the evaluation of visual quality obtained with multifocal IOLS.

Financial Disclosure: No author has a financial or proprietary interest in any material or method mentioned.

J Cataract Refract Surg 2015; 41:613-622 @ 2015 ASCRS and ESCRS

In the past few years, various multifocal intraocular lenses (IOLs) have been developed in an attempt to provide patients with functional visual acuity for all distances. However, to achieve spectacle independence, it is also important to correct significant corneal astigmatism, which is estimated to be present in approximately $30 \%$ of eyes having cataract surgery. ${ }^{1,2}$ To address such problems, recent multifocal IOL models incorporate a toric component, allowing cataract and refractive surgeons to correct almost any refractive error. Nevertheless, despite good visual acuity results, ${ }^{3-6}$ most refractive surgeons will at some point encounter patients who are unhappy with the inadequate quality of their vision. ${ }^{7,8}$ There are many reports of insufficient intermediate vision,, 10 decreased contrast sensitivity, ${ }^{11-13}$ and increased photic phenomena, ${ }^{14,15}$ all which can be sufficiently severe to require IOL explantation. $7,8,16$ 
To understand the visual quality obtained with such multifocal IOLs, it is important to analyze more than just visual acuity and contrast chart results. Photic phenomena might be related to abnormalities in light transmission through ocular media. ${ }^{17}$ Accordingly, recent studies used a double-pass imaging device to analyze intraocular light scattering. Results showed a significant correlation between the objective scatter index and cataract density. ${ }^{18-20}$ This technology also has been successfully applied to patients with phakic IOLs, ${ }^{21}$ eyes with multifocal IOLs, ${ }^{22}$ and even eyes that have had laser corneal ablation procedures. ${ }^{23}$ Although such a device is an effective means for optical quality analysis, the results are provided as quantitative numeric values and therefore do not readily translate the subjective visual experience reported by pseudophakic individuals; namely, as it pertains to assessing the impairment caused by photic phenomena.

Attempts to understand the impact of vision quality on daily activities have resulted in the development of visual function questionnaires ${ }^{24,25}$; however, the application of such questionnaires in everyday clinical practice is not always feasible. Thus, it would be interesting to have a reliable, quick examination to evaluate the overall postoperative visual performance. The light-distortion analyzer is a prototype device developed at the Physics Department, University of Minho, Braga, Portugal, to characterize the size and shape of the light distortion surrounding a central bright light source, such as that visualized by the tested subjects. The results obtained with such a device could theoretically serve as an indicator of visual quality. It would then be interesting to evaluate the light-distortion analyzer results in patients having refractive surgery; namely, those who recently had multifocal IOL implantation.

One of the most recent lines of multifocal IOLs is the AT Lisa brand (Carl Zeiss Meditec AG), which

Submitted: April 7, 2014.

Final revision submitted: June 11, 2014.

Accepted: July 4, 2014.

From the Clínica Oftalmológica das Antas (Brito, Monteiro, Salgado-Borges), the Clinsborges Clínica Oftalmológica (SalgadoBorges), Porto, the Ophthalmology Department, Hospital Privado da Trofa (Brito), Trofa, and the Physics Department (Neves, Meijome), Universidade do Minho, Braga, Portugal.

Presented at the XXXII Congress of the European Society of Cataract and Refractive Surgeons, London, England, September 2014.

Corresponding author: Pedro Silva Brito, MD, Ophthalmology Department, Hospital Privado da Trofa, Rua António Sá Couto de Araújo 105, Trofa, Portugal. E-mail: pbritomd@gmail.com. includes the trifocal $839 \mathrm{M}$ and the bifocal toric 909MP. Such IOLs have a diffractive structure with smooth steps (phase zones) between the principal diffractive zones, which, according to the manufacturer, results in decreased light scattering and improved image quality.

Adopting the perception of light distortion as an indicator of visual quality, we used the lightdistortion analyzer device in patients with the AT Lisa multifocal IOLs to determine possible correlations between visual acuity, residual refractive errors, and light-distortion indices. By comparing the results with those of monofocal IOL cases, we intended to elaborate on the visual quality obtained with these multifocal IOLs.

\section{PATIENTS AND METHODS}

This observational study comprised 2 groups of patients in whom refractive lens exchange (RLE) and implantation of an AT Lisa trifocal 839M (trifocal group) or the bifocal toric 909MP (bifocal toric group) diffractive multifocal IOL were performed. The bifocal toric model was chosen if significant corneal astigmatism ( $\geq 1.00$ diopter [D]) was present. A control group (monofocal group) comprised healthy patients with visually significant cataract who had phacoemulsification and implantation of a 1-piece monofocal IOL (Tecnis ZCB00, Abbott Medical Optics).

All RLE patients met the following inclusion criteria: 48 years or older with significant refractive errors (sphere $\geq 1.50 \mathrm{D}$, cylinder $\geq 1.00 \mathrm{D}$ ) and a manifest desire to obtain spectacle independence. Exclusion criteria included evidence of corneal opacities or irregular astigmatism, history of macular disease, optic neuropathies, and previous corneal or vitreoretinal surgery. Eyes with intraoperative complications, such as posterior capsule rupture or radial capsule tears, did not have multifocal IOL implantation and therefore were not included in this study.

Preoperatively, all patients had a complete ophthalmologic examination including corneal tomography (TMS-5, Tomey Corp.) to rule out ectasia and spectral-domain optical coherence tomography (OCT) (Cirrus HD-OCT, Carl Zeiss Meditec AG) to characterize the macular status. Intraocular lens power was determined using optical biometry (IOLMaster, Carl Zeiss Meditec AG) with the manufacturerlabeled A-constants (118.3 for the multifocal IOLs; 119.3 for the monofocal IOL). The SRK/T formula ${ }^{26}$ was used for axial lengths (ALs) of at least $22.0 \mathrm{~mm}$ and the Haigis formula for ALs lower than $22.0 \mathrm{~mm}$. Biometric values obtained for the multifocal IOL cases were inserted into the Z-Calc application ${ }^{\mathrm{A}}$ to obtain a precise IOL power with a target of emmetropia.

\section{Intraocular Lenses}

The multifocal IOLs were the AT Lisa $839 \mathrm{M}$ and the AT Lisa $909 \mathrm{MP}$. The $909 \mathrm{MP}$ is a diffractive bifocal toric IOL with a $6.0 \mathrm{~mm}$ optic and an overall length of $11.0 \mathrm{~mm}$, providing aspheric aberration correction and a near addition (add) of $+3.75 \mathrm{D}$ at the IOL plane. It is of a foldable hydrophilic acrylic material with hydrophobic surface properties, and its single-piece 4-haptic design allows implantation in the capsular bag through incisions as small as $1.8 \mathrm{~mm}$. 
Two opposing lines visible in the outer part of the IOL optic provide guidance for correct alignment of the IOL with the steeper meridian of the cornea. The asymmetric light distribution profile allocates $65 \%$ of light to the distant focus and $35 \%$ to the near focus, regardless of pupil size.

The multifocal $839 \mathrm{M}$ is a nontoric diffractive multifocal IOL very similar to the bifocal toric model but has trifocal properties, providing a near add of $+3.33 \mathrm{D}$ and an intermediate add of $+1.66 \mathrm{D}$ at the IOL plane. The trifocal zone is in the central $4.34 \mathrm{~mm}$ of the IOL optic, and the remaining peripheral area is bifocal to optimize night vision. It also has asymmetric light-distribution properties, allocating $50 \%, 20 \%$, and $30 \%$ of light to the far, intermediate, and near foci, respectively.

The control group had implantation of a 1-piece Tecnis ZCB00 IOL. This monofocal IOL is of a hydrophobic acrylic material with a $6.0 \mathrm{~mm}$ diameter optic, biconvex shape, and anterior aspheric surface. It has an overall diameter of $13.0 \mathrm{~mm}$ and offset loop haptics that allow stable 3-point capsular bag fixation.

\section{Surgical Technique}

One of 2 surgeons (M.M., J.S.B.) performed the RLE and cataract surgery procedures using a standard phacoemulsification technique (Infiniti Vision System, Alcon Laboratories, Inc.) through a $2.2 \mathrm{~mm}$ clear corneal incision placed on the 120-degree corneal meridian. A continuous curvilinear capsulorhexis with a target diameter of $5.5 \mathrm{~mm}$ diameter was created. The IOL was placed in the capsular bag, and extra care was taken when aspirating the ophthalmic viscosurgical device (OVD) to ensure correct and sustainable IOL centration. In eyes having toric IOLs implantation, the 180degree meridian was marked with the patient seated at the slitlamp using a Geuder horizontal marker (G-33763) and the steep corneal meridian was marked intraoperatively using a Geuder measuring ring (G-33762). Correct IOL orientation was assessed when the IOL was being implanted in the bag and after OVD aspiration (Figure 1). Postoperatively, patients were prescribed dexamethasone $0.1 \%$, ofloxacin $0.3 \%$, and flurbiprofen $0.3 \%$ eyedrops 4 times a day for 3 weeks.

\section{Light-Distortion Analysis Protocol}

The clinical records of all patients having surgery between November 2012 and September 2013 were retrospectively reviewed. The following clinical variables were retrieved: age, sex, preoperative uncorrected distance visual acuity (UDVA), corrected distance visual acuity (CDVA), preoperative manifest refraction, keratometry $(\mathrm{K})$ readings, $\mathrm{AL}, \mathrm{IOL}$ dioptric power, and follow-up time. All cases were then sequentially scheduled for a complete postoperative ophthalmologic examination including UDVA and CDVA determination using a Snellen chart at $6 \mathrm{~m}$, uncorrected near visual acuity (UNVA) and corrected near visual acuity (CNVA) measured with a Jaeger chart at $33 \mathrm{~cm}$, slitlamp biomicroscopy, Goldmann applanation tonometry, fundoscopy, and tear-film evaluation by the Schirmer test.

Exclusion criteria for examination with the light-distortion analyzer device were the following: any sign of corneal disease as well as a Schirmer test of less than $10.0 \mathrm{~mm}$, any degree of posterior capsule opacification (PCO), and visible IOL decentration or tilt. In this study, cases with Sjögren syndrome, rheumatic diseases, diabetes mellitus, or a history of

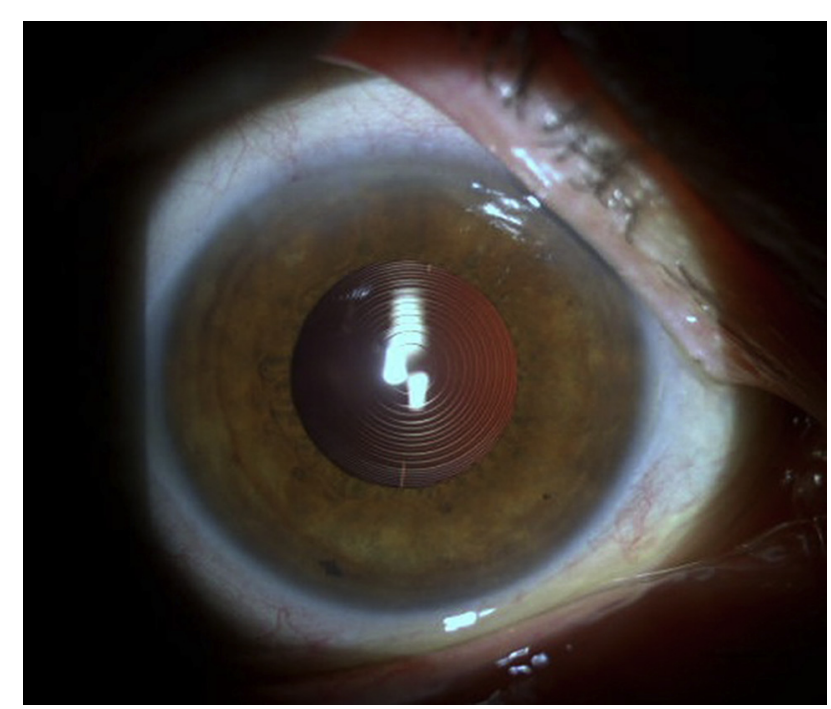

Figure 1. Slitlamp photograph of the bifocal toric IOL aligned with the corneal meridian at 80 degrees in a patient with a preoperative refraction of $-5.00-1.25 \times 180$ and $2.03 \mathrm{D}$ of corneal astigmatism at 168 degrees. With 8 months of follow-up, a $-0.75 \mathrm{D}$ postoperative refraction was verified, indicating stable toric correction.

radiotherapy were also excluded to minimize the effect of significant dry-eye disease.

After slitlamp examination, all included cases had lightdistortion evaluation with the light-distortion analyzer and wavefront aberrometry (Wavescan Wavefront System, Abbott Medical Optics, Inc.).

The light-distortion analyzer (HLMP-CW47-RU000, Agilent Technologies) is an experimental device consisting of a central white light-emitting diode (LED) surrounded by 240 small, white LEDs (HSMW-CL25, Avago Technologies) distributed in 24 semimeridians with an angular separation of 15 degrees and covering an area of 10 degrees at a $2 \mathrm{~m}$ examination distance (Figure 2). The physical display device is connected to a computer with dedicated software. The subject being evaluated provides feedback to the system through a remote response device. Peripheral stimuli (the smaller LEDs) are presented around the central source of light from the inner to the outer part of the test field at random time intervals from 250 to 750 milliseconds. Semimeridians are explored in random order. The subject was seated $2 \mathrm{~m}$ from the display device in a darkened room and was instructed to press the response device as soon as the small LED was visualized as distinct from the central white LED. With each response, the system proceeds to the next semimeridian, and the process repeats until all meridians are tested. The test was performed first on the right eye, then on the left eye, and finally binocularly.

Once the testing procedure is complete, the software calculates several indices that determine the size and regularity of the distortion surrounding the central source of light. The distortion index is calculated as the ratio of the area of points missed by the subject and the total area explored and is expressed as a percentage. The best-fit circle radius is defined as the circle that best fits the distortion area resulting from the linear binding of all points in each meridian of the device. This parameter is expressed in millimeters and is linearly related to the light-distortion index parameter. The higher 


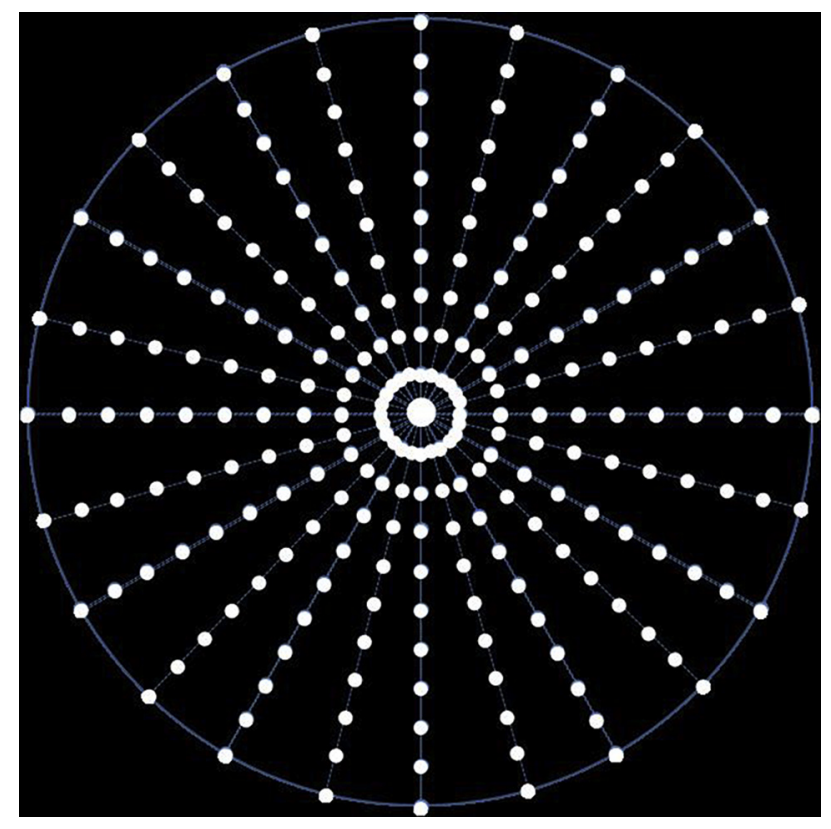

Figure 2. Distribution of the main central light source and smaller peripheral light stimuli in accordance with the display used in the prototype light-distortion analyzer.

the values of the best-fit circle radius and light-distortion index, the lower the ability to discriminate small light stimuli surrounding a central source of light. The deviation of the obtained polygonal shape from the best-fit circle fit is called the best-fit circle irregularity. The standard deviation of the best-fit circle irregularity measures the asymmetry of the actual limits of the distortion from the perfect circular shape of the best-fit circle and indicates the light-distortion irregularity.

For each case, the light-distortion testing procedure was performed 3 times with the subject wearing spectacle correction. The values obtained on the third examination were chosen for statistical analysis.

\section{Statistical Analysis}

All results were analyzed using SPSS for Windows software (version 19.0, International Business Machines Corp.). Evaluation of data normality was performed using the Kolmogorov-Smirnov test. Parametric variables were compared using 1-way analysis of variance with Tukey post hoc analysis. When comparing data between 2 groups, the Student $t$ test for independent samples was used. For comparison of preoperative data and postoperative data, the paired-samples $t$ test was used. For nonparametric variables, the Kruskal-Wallis test was used to assess the significance of differences between the 3 groups or the Mann-Whitney $U$ test to compare values between 2 independent groups. The Wilcoxon signed-rank test was used to compare paired nonparametric data. Significant correlations were assessed using Pearson or Spearman correlation coefficients according to the normality of data. A $P$ value less than 0.05 was considered significant for all tests.

\section{RESULTS}

The study enrolled 66 eyes of 34 patients divided into 3 study groups. The trifocal group comprised 33 eyes;

\begin{tabular}{|c|c|c|c|c|}
\hline Parameter & Trifocal Group & Toric Bifocal Group & Monofocal Group & $P$ Value \\
\hline $\operatorname{Sex}(n)$ & & & & .522 \\
\hline Male & 8 & 5 & 4 & \\
\hline Female & 8 & 3 & 5 & \\
\hline Mean age $(y) \pm S D$ & $57.93 \pm 6.60$ & $57.14 \pm 11.34$ & $63.17 \pm 2.81$ & .052 \\
\hline \multicolumn{5}{|l|}{ Sphere (D) } \\
\hline Mean \pm SD & $+0.86 \pm 1.62$ & $-0.36 \pm 3.87$ & $-0.31 \pm 1.98$ & .233 \\
\hline Range & $-2.50,+4.25$ & $-7.50,+7.00$ & $-3.00,+2.25$ & \\
\hline \multicolumn{5}{|l|}{ Cylinder (D) } \\
\hline Mean $\pm S D$ & $-0.69 \pm 0.46$ & $-1.93 \pm 1.21$ & $-0.86 \pm 0.51$ & $<.001$ \\
\hline Range & $-1.50,0.00$ & $-4.50,-1.00$ & $-1.75,0.00$ & \\
\hline \multicolumn{5}{|l|}{ Corneal astigmatism (D) } \\
\hline Mean \pm SD & $0.59 \pm 0.36$ & $1.87 \pm 0.91$ & $0.62 \pm 0.46$ & $<.001$ \\
\hline Range & $0.17,1.06$ & $1.08,4.50$ & $0.09,1.41$ & \\
\hline \multicolumn{5}{|l|}{ Axial length (mm) } \\
\hline Mean $\pm S D$ & $23.24 \pm 0.79$ & $23.72 \pm 1.46$ & $23.12 \pm 0.71$ & .490 \\
\hline Range & $22.04,24.72$ & $21.11,26.37$ & $22.31,24.30$ & \\
\hline \multicolumn{5}{|l|}{ IOL sphere (D) } \\
\hline Mean \pm SD & $21.22 \pm 1.95$ & $19.56 \pm 4.99$ & $21.24 \pm 1.28$ & .278 \\
\hline Range & $17.00,26.00$ & $8.00,28.00$ & $16.50,24.00$ & \\
\hline Mean IOL cylinder $(\mathrm{D}) \pm \mathrm{SD}$ & - & $1.86 \pm 0.85$ & - & - \\
\hline Mean follow-up (mo) $\pm S D$ & $10.27 \pm 4.16$ & $7.13 \pm 3.48$ & $8.55 \pm 2.17$ & .012 \\
\hline
\end{tabular}


the bifocal toric group, 15 eyes; and the monofocal group, 18 eyes.

Table 1 shows the demographic and preoperative data by IOL group. Patients in the multifocal IOL groups were younger than those in the monofocal IOL group, although the difference was not statistically significant $(P=.052)$. There was also no difference in the ratio of men to women. The mean follow-up time was significantly lower in the bifocal toric group $(P=.012)$, although no difference was found between the trifocal group and the control group. The mean flat $\mathrm{K}$ value was lower in the bifocal toric group $(42.35 \mathrm{D})$ than in the trifocal group $(43.69 \mathrm{D})$ or the control group (43.34 D) $(P=.023)$, corresponding to statistically significantly higher corneal astigmatism values in the bifocal toric group and therefore a significantly higher preoperative cylinder power (both $P<.001$ ). The mean pupil diameter overall was $5.78 \mathrm{~mm} \pm 1.04$ (SD), with no significant difference between thee 3 IOL groups. There was also no significant between-group difference in the mean preoperative manifest sphere (overall $0.25 \pm 2.45 \mathrm{D}$; range -7.50 to $+7.00 \mathrm{D}$ ), $\mathrm{AL}$ (overall
$23.34 \pm 0.97 \mathrm{~mm}$; range 21.11 to $26.37 \mathrm{~mm}$ ), or IOL spherical power (overall $20.70 \pm 3.26 \mathrm{D}$; range 8.00 to $28.00 \mathrm{D})$.

\section{Visual Acuity and Refraction}

Between Groups Table 2 shows the overall postoperative visual and refractive outcomes. All 3 groups had a statistically significant improvement in UDVA and CDVA (both $P=.001$ ). The postoperative refractive sphere was less than $1.00 \mathrm{D}$ in 63 cases $(95.4 \%)$, with $38(57.8 \%)$ attaining a residual sphere of less than $0.50 \mathrm{D}$. There was no statistically significant difference in UDVA, CDVA, or UNVA between the 2 multifocal groups; however, the mean UNVA was statistically significantly worse than the mean CNVA in the monofocal IOL group $(P<.001)$. The mean CNVA was similar in the 2 multifocal groups and worse than in the monofocal group, although the differences were not statistically significant $(P=.303)$.

There were no statistically significant differences in postoperative refractive sphere between the 3 groups.

Table 2. Visual and refractive outcomes by IOL group.

\begin{tabular}{|c|c|c|c|c|}
\hline Parameter & Trifocal Group & Toric Bifocal Group & Monofocal Group & $P$ Value \\
\hline \multicolumn{5}{|c|}{ Preop UDVA (logMAR) } \\
\hline Mean \pm SD & $0.136 \pm 0.097$ & $0.356 \pm 0.356$ & $0.305 \pm 0.105$ & \multirow[t]{2}{*}{$<.001$} \\
\hline Range & $0.05,0.50$ & $0.05,1.00$ & $0.20,0.50$ & \\
\hline \multicolumn{5}{|c|}{ Postop UDVA (logMAR) } \\
\hline Mean $\pm S D$ & $0.022 \pm 0.037$ & $.042 \pm 0.045$ & $0.051 \pm 0.037$ & \multirow[t]{2}{*}{.010} \\
\hline Range & $0.00,0.15$ & $00.00,0.10$ & $0.00,0.10$ & \\
\hline \multicolumn{5}{|c|}{ Preop CDVA (logMAR) } \\
\hline Mean \pm SD & $0.010 \pm 0.024$ & $0.043 \pm 0.041$ & $0.273 \pm 0.108$ & \multirow[t]{2}{*}{$<.001$} \\
\hline Range & $0.00,0.10$ & $0.00,0.10$ & $0.10,0.50$ & \\
\hline \multicolumn{5}{|c|}{ Postop CDVA (logMAR) } \\
\hline Mean \pm SD & $0.001 \pm 0.008$ & $0.010 \pm 0.020$ & $0.008 \pm 0.018$ & \multirow[t]{2}{*}{.133} \\
\hline Range & $0.00,0.05$ & $0.00,0.05$ & $0.00,0.05$ & \\
\hline \multicolumn{5}{|c|}{ Preop CNVA (logMAR) } \\
\hline Mean \pm SD & $0.021 \pm 0.025$ & $0.048 \pm 0.049$ & $0.171 \pm 0.060$ & \multirow[t]{2}{*}{$<.001$} \\
\hline Range & $0.00,0.05$ & $0.00,0.18$ & $0.00,0.30$ & \\
\hline \multicolumn{5}{|c|}{ Postop UNVA (logMAR) } \\
\hline Mean \pm SD & $0.123 \pm 0.054$ & $0.130 \pm 0.068$ & - & \multirow[t]{2}{*}{.540} \\
\hline Range & $0.00,0.20$ & $0.00,0.20$ & - & \\
\hline \multicolumn{5}{|c|}{ Postop CNVA (logMAR) } \\
\hline Mean \pm SD & $0.017 \pm 0.029$ & $0.026 \pm 0.041$ & $0.006 \pm 0.015$ & \multirow[t]{2}{*}{.303} \\
\hline Range & $0.00,0.10$ & $0.00,0.10$ & $0.00,0.04$ & \\
\hline \multicolumn{5}{|c|}{ Postop sphere (D) } \\
\hline Mean $\pm S D$ & $-0.03 \pm 0.44$ & $0.28 \pm 0.62$ & $-0.092 \pm 0.304$ & \multirow[t]{2}{*}{.175} \\
\hline Range & $-0.75,+1.00$ & $-0.75,+1.50$ & $-0.75,+0.50$ & \\
\hline \multicolumn{5}{|c|}{ Postop cylinder (D) } \\
\hline Mean \pm SD & $-0.43 \pm 0.36$ & $-0.41 \pm 0.41$ & $-0.776 \pm 0.310$ & \multirow[t]{2}{*}{.014} \\
\hline Range & $-1.00,-0.25$ & $-1.25,0.00$ & $-1.25,-0.25$ & \\
\hline
\end{tabular}


However, the postoperative refractive cylinder was statistically significantly higher in the monofocal group than in the 2 multifocal groups $(P=.014)$.

No significant between-group differences were found in wavefront root-mean-square (RMS) total aberrations, RMS higher-order aberrations, mean coma, or mean spherical aberration.

Trifocal Group Analysis of the change in refraction and visual acuity by IOL group showed that the trifocal group had a statistically significant improvement in UDVA $(P<.001)$, with 30 cases $(90.9 \%)$ obtaining a UDVA better than $0.1 \log$ MAR and all obtaining a CDVA better than $0.1 \log$ MAR $(P=.02)$. There were significant reductions in spherical power $(P=.007)$ and cylindrical power $(P=.007)$. The subjective spherical power was less than $0.50 \mathrm{D}$ in 17 cases (51.5\%). The UNVA was $0.1 \log$ MAR or better in 20 cases $(60.6 \%)$. Significant correlations were found between postoperative UDVA and IOL power $(P=$ $.007)$ and between postoperative UDVA and postoperative refractive cylinder $(P=.049)$. Significant correlations were also found between UNVA and corneal astigmatism $(P=.044)$ and between UNVA and postoperative cylinder $(P=.003)$. The latter variable was also significantly correlated with higher RMS total aberrations $(P<.001)$.

Bifocal Toric Group The bifocal toric group had significant improvements in UDVA $(P=.004)$, with 9 cases $(60.0 \%)$ obtaining a UDVA better than $0.1 \log$ MAR and all obtaining a CDVA better than 0.1 logMAR $(P=.015)$. The postoperative refractive sphere $(P=.008)$ and cylinder $(P=.004)$ were also significantly improved. The subjective spherical power was less than $0.50 \mathrm{D}$ in 9 cases $(60.0 \%)$, and the subjective cylinder was less than $1.00 \mathrm{D}$ in 13 cases $(86.7 \%)$. The mean cylinder reduction was $1.53 \pm 1.33 \mathrm{D}$, corresponding to $71.46 \%$ of mean cylinder magnitude. This favorable outcome was seen equally in cases with corneal astigmatism of $2.00 \mathrm{D}$ or less and in cases with more than $2.00 \mathrm{D}$ of corneal astigmatism $(P=.571$, Fisher exact test $)$. There were significant correlations between postoperative UDVA and postoperative subjective sphere $(P=.012)$ and between postoperative UDVA and cylinder $(P<.001)$. There were also significant correlations between UNVA and postoperative subjective sphere $(P<.001)$ and between UNVA and cylinder $(P=.028)$.

Monofocal Group The monofocal group had a statistically significant improvement in UDVA $(P<.001)$, with 12 cases $(66.7 \%)$ obtaining a UDVA better than $0.1 \log$ MAR and all obtaining a CDVA better than $0.1 \log$ MAR $(P<.001)$. A significant reduction in spherical power $(P<.001)$ was found, with all cases

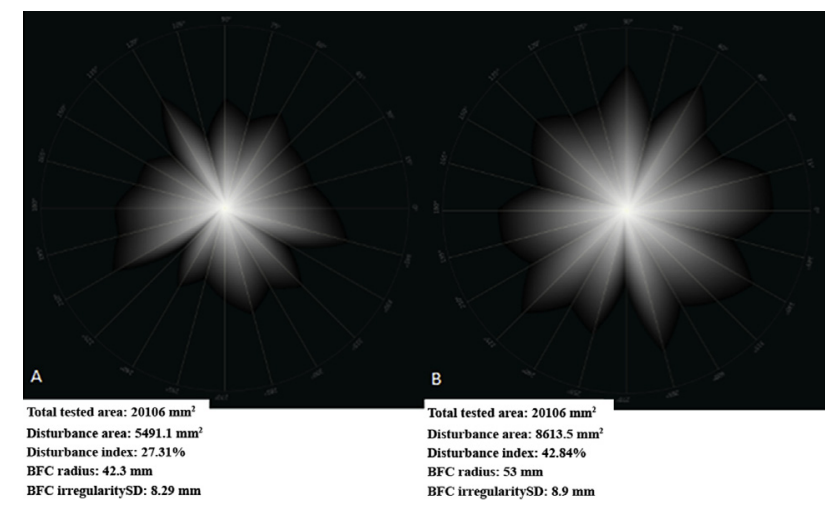

Figure 3. A: Light distortion analyzer results in a 67-year-old patient with a monofocal IOL, indicating a distortion index of $27 \%$ with a postoperative refraction of $+1.00-0.75 \times 180$. B: Light-distortion analyzer results in a 63-year-old patient with a trifocal IOL, indicating a distortion index of $43 \%$ with a postoperative refraction of $+0.50-0.50 \times 155$ (BFC $=$ best-fit circle).

achieving a residual sphere inferior to $1.00 \mathrm{D}$ and 6 cases $(33.3 \%)$ obtaining a spherical refraction inferior to $0.50 \mathrm{D}$. No significant change was found in the postoperative refractive cylindrical power $(P=.487)$. A significant correlation was found between the postoperative UDVA and the postoperative cylindrical power $(P=.001)$.

\section{Light Distortion}

Between Groups The mean light-distortion index and best-fit circle radius were significantly lower in the monofocal group than in the multifocal groups $(P<.001)$ (Figure 3). The light-distortion irregularity index was significantly higher in the bifocal toric group than in the monofocal or trifocal group (Table 3).

There was no significant difference in the lightdistortion index or best-fit circle radius between the 2 multifocal groups, despite a tendency toward higher values in the bifocal toric group. In contrast, the lightdistortion irregularity was statistically significantly higher in the bifocal toric group $(P=.015)$.

No significant correlations were found between the light-distortion index or best-fit circle radius and the following clinical variables: age, sex, preoperative sphere, preoperative cylinder, AL, IOL sphere power, IOL cylinder power, corneal K values, pupil size, postoperative UDVA, CDVA, or CNVA. A nearly significant correlation with postoperative follow-up time was seen for light-distortion index $(P=.058)$ and best-fit circle radius $(P=.051)$.

Trifocal Group In the trifocal group, a significant correlation was found between the light-distortion index and follow-up time $(P=.007)$. Also, the lightdistortion irregularity correlated significantly with 
Table 3. Light-distortion analyzer results by study group.

\begin{tabular}{lccc}
\hline & \multicolumn{3}{c}{ Mean \pm SD } \\
\cline { 2 - 4 } Parameter & Trifocal Group & Toric Bifocal Group & Monofocal Group \\
\hline $\begin{array}{l}\text { Light-distortion index (\%) } \\
\quad \text { Monocular }\end{array}$ & $46.97 \pm 17.27$ & $53.57 \pm 18.55$ & \\
$\quad$ Binocular & $29,29 \pm 9.19$ & $40.49 \pm 12.00$ & $23.94 \pm 14.89$ \\
$\begin{array}{l}\text { Best-fit circle radius (mm) } \\
\quad \text { Monocular }\end{array}$ & $55.28 \pm 10.03$ & $58.89 \pm 10.86$ & $15.28 \pm 6.87$ \\
$\quad$ Binocular & $43.84 \pm 6.83$ & $47.84 \pm 11.04$ & $38.14 \pm 12.09$ \\
$\begin{array}{l}\text { Light-distortion irregularity } \\
\text { (mm) }\end{array}$ & & & $28.24 \pm 8.01$ \\
$\quad \begin{array}{l}\text { Monocular } \\
\text { Binocular }\end{array}$ & $5.71 \pm 3.15$ & $7.25 \pm 3.58$ & \\
\end{tabular}

the postoperative sphere $(P=.010)$ and corneal astigmatism $(P=.015)$.

Bifocal Toric Group In the bifocal toric group, a significant direct correlation was found between the lightdistortion index and the postoperative subjective sphere $(P=.001)$. Also, a significant inverse correlation was found with the postoperative cylinder refraction $(P=.012)$. The light-distortion irregularity was also correlated with postoperative subjective sphere power $(P=.003)$.

Monofocal Group In the monofocal group, that there was a significant inverse correlation between the light-distortion index and the postoperative cylinder $(P=.001)$. No significant correlations for lightdistortion irregularity were found.

Binocular Conditions Light-distortion indices were significantly lower when measured under binocular conditions in all IOL groups $(P<.001$, lightdistortion index, best-fit circle radius; $P=.04$, lightdistortion irregularity). The light-distortion analyzer outcomes in 9 cases with bilateral monofocal IOLs were better than in the 15 cases with bilateral trifocal IOLs $(P<.001$, light-distortion index; $P=.041$, light-distortion irregularity) and than in the 6 cases with bilateral bifocal toric IOLs $(P<.001$, lightdistortion index; $P=.017$, light-distortion irregularity). Comparison of the 2 multifocal groups showed a statistically significantly lower light-distortion index in the trifocal group $(P=.035)$.

\section{DISCUSSION}

The development of presbyopia-correcting IOLs and the availability of precise optical biometry measurements has been a major clinical breakthrough in ophthalmology in the past few years. It is rewarding to verify that with modern IOL calculation technology, reliable refractive correction is a realistic outcome.
Such accuracy is particularly important in the case of multifocal IOLs because it has been reported that a residual cylinder of $1.50 \mathrm{D}$ has a significant impact on the optical performance of diffractive multifocal IOLs. ${ }^{27}$ Accordingly, the majority $(57.8 \%)$ of our cases obtained a residual sphere of less than $0.50 \mathrm{D}$ and $86.7 \%$ of cases with the AT Lisa 909 MP bifocal toric IOL achieved a stable residual cylinder of less than $1.00 \mathrm{D}$. Such results are similar to the percentages reported by Visser et al. ${ }^{28}$ and Bellucci et al., ${ }^{29}$ indicating the effectiveness of the IOL in correcting corneal astigmatism. That the residual cylinder refraction was significantly correlated not only with uncorrected distance and near visual acuities but also with the light-distortion index in the trifocal group (AT Lisa 839M IOL) and monofocal group (Tecnis ZCB00 IOL) (the 2 groups including cases with significant corneal astigmatism) underlines the importance of correcting preoperative corneal astigmatism to obtain the best visual outcomes.

In this study, patients in both multifocal IOL groups achieved satisfactory UNVA. The mean UNVA was $0.123 \pm 0.054 \operatorname{logMAR}$ in the trifocal group and $0.130 \pm 0.068 \log$ MAR in the bifocal toric group, results that are better than those in previous studies. ${ }^{5,6,28,29}$ Although different study methodologies, namely in near visual acuity assessment, explain some differences in the UNVA results, we believe the good outcomes in our series can at least in part be explained by a series of clinical aspects. That is, all our cases were purely RLE procedures because no eye had visually significant lens opacity. Thus, the mean age was somewhat lower than in previous studies $^{28,29}$ and patients had a strong motivation for spectacle-free vision. In addition, attention was given to tear-film function by excluding cases with systemic conditions potentiating dry-eye disease and by carefully evaluating the tear-film status during slitlamp ophthalmologic examination. Dry-eye disease 
should not be taken lightly when considering multifocal IOL implantation. In a recent study, there was significantly increased ocular light scattering in cases with mild to moderate dry eye. ${ }^{30}$ Considering that diffractive multifocal IOL optics imply simultaneous light distribution to different focal points, the impact of dry eye-induced light scattering will add to an overall diminished visual quality. Also, even though the bifocal toric IOL has a near add of $3.75 \mathrm{D}$ versus the $3.33 \mathrm{D}$ add of the trifocal IOL as well as a higher percentage of light assigned to the near focus, patients with the trifocal IOL had slightly better UNVA outcomes than those with the bifocal toric IOL. This could be partially explained by the lower mean follow-up time in the bifocal toric group; it is well known that by the process of neuroadaptation, visual acuity with multifocal IOLs tends to improve over time. More important, in both multifocal IOL groups, there were significant correlations between residual refractive error and UNVA. More specifically, the bifocal toric group had a higher residual hyperopic error that might have nullified its superior near add. This is an important observation because the bifocal toric group in this study represents our first cases of implantation of that type of IOL; thus, there was an inherent learning curve before optimum visual and refractive results could be obtained. Nevertheless, both multifocal IOLs provided satisfying UNVA; more important, all RLE patients were satisfied with the overall visual outcomes and with the level of spectacle independence postoperatively.

Considering light-distortion analyzer results, despite the similar CDVA and patient age between the 3 groups, the multifocal IOL groups had a significantly higher light-distortion index. This means that the light-distortion analyzer reliably identified a subjective component of vision, distinct from Snellen chart visual acuity. To our knowledge, this is the first study to use an experimental device to quantify the subjective perception of light distortion after lens surgery. Previous studies evaluated intraocular straylight after multifocal IOL implantation, ${ }^{22,31}$ reporting significant levels of straylight in multifocal IOLs compared with levels in monofocal IOLs. ${ }^{31,32}$ Similar to such reports, our patients had no signs of PCO or ocular surface disease, and the light-distortion analyzer examination was performed under best refractive correction to nullify refractive defocus, leading us to believe that the increased light-distortion index in the multifocal IOL groups is related to the diffractive optics system of current multifocal IOLs. Nevertheless, we verified that the addition of a focal point for intermediate distance vision (present in the AT Lisa 839M IOL) did not cause a significant increase in light-distortion indices compared with the bifocal toric AT Lisa
909 MP IOL. Finally, we found that the lightdistortion indices significantly improved under binocular viewing conditions, corroborating the current knowledge that multifocal IOLs perform better when implanted bilaterally. ${ }^{33}$

The main advantage of the light-distortion analyzer over other devices, such as the Optical Quality Analysis System (Visiometrics) or the C-Quant (Oculus), is that the results are displayed as an approximate graphic representation of the light distortion as visualized by the patient, giving a qualitative characteristic to the results. Although still in its early stages, we believe the use of ocular light-transmission analyzers will become indispensable in the postoperative evaluation of the quality of vision conferred by multifocal IOLs. In that sense, the light-distortion analyzer might be helpful when studying cases of bothersome positive dysphotopsia and therefore allow the surgeon to determine whether IOL explantation is warranted.

Considering that multifocal IOLs are gaining favor as the lens surgery of choice to correct presbyopia, ${ }^{34}$ it will be interesting to apply this technology to different multifocal IOL models to characterize overall visual quality.

Overall our results are in accordance with current consensus $^{35,36}$ that spectacle-free functional visual acuity is a real possibility for lens surgery candidates. Nevertheless, it is clear that the surgeon still faces a tradeoff between offering the best possible visual quality with a monofocal IOL and progressive spectacles or providing spectacle independence with a multifocal IOL, but with reduced optical performance resulting from the simultaneous focal points. It seems that despite all technological progress, the role of the surgeon is still the key to patient satisfaction, which continues to rely on judicious clinical assessment. A recent review paper by the American Society of Cataract and Refractive Surgery Cataract Clinical Committee ${ }^{37}$ detailed several clinical characteristics that can help surgeons identify ideal candidates for multifocal IOLs. In our opinion, the most important factor is good clinical assessment of patient motivation for spectacle-free vision complemented by a thorough ophthalmologic examination with particular attention to the status of the ocular surface.

In conclusion, in this study the 2 AT Lisa diffractive multifocal IOL models provided excellent visual and refractive outcomes. In addition, we described an experimental methodology to characterize the perception of light distortion. In the future, the application of devices, such as the light-distortion analyzer, to evaluate the visual outcomes with several presbyopic IOLs will provide clues to the expected overall optical performance. 


\section{WHAT WAS KNOWN}

- The current state of multifocal IOL technology implies a tradeoff between increased focal depth and thus reduced optical quality. Nevertheless, the availability and application of techniques to evaluate the propensity for postoperative photic phenomena remain limited.

\section{WHAT THIS PAPER ADDS}

- A new prototype device evaluated the perception of light distortion after IOL surgery, indicating significantly increased distortion indices with diffractive multifocal IOLs, despite patient age and CDVA values similar to those in the monofocal IOL group.

- The results suggest that the routine use of such a device might become an adjunct way to study visual performance obtained with different multifocal IOLS.

\section{REFERENCES}

1. Hoffer KJ. Biometry of 7,500 cataractous eyes. Am J Ophthalmol 1980; 90:360-368

2. Hoffmann PC, Hütz WW. Analysis of biometry and prevalence data for corneal astigmatism in 23,239 eyes. J Cataract Refract Surg 2010; 36:1479-1485

3. Packer M, Chu YR, Waltz KL, Donnenfeld ED, Wallace RB III, Featherstone K, Smith P, Bentow SS, Tarantino N. Evaluation of the aspheric Tecnis multifocal intraocular lens: one-year results from the first cohort of the Food and Drug Administration clinical trial. Am J Ophthalmol 2010; 149:577-584. Available at: http://www.ajo.com/article/S0002-9394(09http://www.ajo.com/ article/S0002-9394(09)00810-1/pdf. Accessed November 19, 2014

4. Gierek-Ciaciura S, Cwalina L, Bednarski L, Mrukwa-Kominek E. A comparative clinical study of the visual results between three types of multifocal lenses. Graefes Arch Clin Exp Ophthalmol 2010; 248:133-140

5. Mojzis P, Peña-García P, Liehneova I, Ziak P, Alió JL. Outcomes of a new diffractive trifocal intraocular lens. J Cataract Refract Surg 2014; 40:60-69

6. Alió JL, Piñero DP, Tomás J, Plaza AB. Vector analysis of astigmatic changes after cataract surgery with implantation of a new toric multifocal intraocular lens. J Cataract Refract Surg 2011; 37:1217-1229

7. de Vries NE, Webers CAB, Touwslager WRH, Bauer NJC, de Brabander J, Berendschot TT, Nuijts RMMA. Dissatisfaction after implantation of multifocal intraocular lenses. J Cataract Refract Surg 2011; 37:859-865

8. Woodward MA, Randleman JB, Stulting RD. Dissatisfaction after multifocal intraocular lens implantation. J Cataract Refract Surg 2009; 35:992-997

9. Hütz WW, Eckhardt HB, Röhrig B, Grolmus R. Intermediate vision and reading speed with array, Tecnis, and ReSTOR intraocular lenses. J Refract Surg 2008; 24:251-256

10. Blaylock JF, Si Z, Vickers C. Visual and refractive status at different focal distances after implantation of the ReSTOR multifocal intraocular lens. J Cataract Refract Surg 2006; 32:1464-1473

11. Fernández-Vega L, Alfonso JF, Baamonde B, Madrid-Costa D, Montés-Micó R, Lozano J. Visual and refractive outcomes in hyperopic pseudophakic patients implanted with the Acri.LISA 366D multifocal intraocular lens. Am J Ophthalmol 2009; 148:214-220

12. Zhao G, Zhang J, Zhou Y, Hu L, Che C, Jiang N. Visual function after monocular implantation of apodized diffractive multifocal or single-piece monofocal intraocular lens; randomized prospective comparison. J Cataract Refract Surg 2010; 36:282-285

13. Alió JL, Plaza-Puche AB, Piñero DP, Amparo F, RodríguezPrats JL, Ayala MJ. Quality of life evaluation after implantation of 2 multifocal intraocular lens models and a monofocal model. J Cataract Refract Surg 2011; 37:638-648

14. Souza CE, Muccioli C, Soriano ES, Chalita MR, Oliveira F, Freitas LL, Meire LP, Tamaki C, Belfort R Jr. Visual performance of AcrySof ReSTOR apodized diffractive IOL: a prospective comparative trial. Am J Ophthalmol 2006; 141:827-832

15. Sen HN, Sarikkola A-U, Uusitalo RJ, Laatikainen L. Quality of vision after AMO Array multifocal intraocular lens implantation. J Cataract Refract Surg 2004; 30:2483-2493

16. Galor A, Gonzalez M, Goldman D, O’Brien TP. Intraocular lens exchange surgery in dissatisfied patients with refractive intraocular lenses. J Cataract Refract Surg 2009; 35:1706-1710

17. van den Berg TJTP. Importance of pathological intraocular light scatter for visual disability. Doc Ophthalmol 1986; 61:327-333

18. Artal P, Benito A, Pérez GM, Alcón A, De Casas Á, Pujol J, Marín J. An objective scatter index based on double-pass retinal images of a point source to classify cataracts. PLoS One 2010; 6(2):e16823. Available at: http://www.ncbi.nIm. nih.gov/pmc/articles/PMC3033912/pdf/pone.0016823.pdf. Accessed November 19, 2104

19. Cabot F, Saad A, McAlinden C, Haddad NM, Grise-Dulac A, Gatinel D. Objective assessment of crystalline lens opacity level by measuring ocular light scattering with a double-pass system. Am J Ophthalmol 2013; 155:629-635

20. Vilaseca M, Romero MJ, Arjona M, Luque SO, Ondategui JC, Salvador A, Güell JL, Artal P, Pujol J. Grading nuclear, cortical and posterior subcapsular cataracts using an objective scatter index measured with a double-pass system. $\mathrm{Br} \mathrm{J}$ Ophthalmol 2012; 96:1204-1210

21. Kamiya K, Shimizu K, Saito A, Igarashi A, Kobashi H. Comparison of optical quality and intraocular scattering after posterior chamber phakic intraocular lens with and without a central hole (Hole ICL and Conventional ICL) implantation using the double-pass instrument. PLoS One 2013; 8(6):e66846. Available at: http://www. plosone.org/article/ fetchObject.action? uri=info\%3Adoi\%2F10.1371\%2Fjournal. pone.0066846\&repesentation =PDF. Accessed November 19, 2014

22. Castillo-Gómez A, Carmona-González D, Martínez-de-la-Casa JM, Palomino-Bautista C, García-Feijoo J. Evaluation of image quality after implantation of 2 diffractive multifocal intraocular lens models. J Cataract Refract Surg 2009; 35:1244-1250

23. Ondategui JC, Vilaseca M, Arjona M, Montasell A, Cardona G, Güell JL, Pujol J. Optical quality after myopic photorefractive keratectomy and laser in situ keratomileusis: comparison using a double-pass system. J Cataract Refract Surg 2012; 38:16-27

24. Mangione CM, Lee PP, Gutierrez PR, Spritzer K, Berry S, Hays RD. for the National Eye Institute Visual Function Questionnaire Field Test Investigators. Development of the 25-item National Eye Institute Visual Function Questionnaire. Arch Ophthalmol 2001; 119:1050-1058. Available at: http://archopht. 
jamanetwork.com/data/Journals/OPHTH/6709/EEB90033.pdf. Accessed November 19, 2014

25. McAlinden C, Pesudovs K, Moore JE. The development of an instrument to measure quality of vision: the Quality of Vision (QoV) questionnaire. Invest Ophthalmol Vis Sci 2010; 51:5537-5545. Available at: http://www.iovs.org/content/51/11/5537.full.pdf. Accessed November 19, 2014

26. Retzlaff JA, Sanders DR, Kraff MC. Development of the SRK/T intraocular lens implant power calculation formula. J Cataract Refract Surg 1990; 16:333-340; erratum, 528

27. Hayashi K, Manabe S-i, Yoshida M, Hayashi H. Effect of astigmatism on visual acuity in eyes with a diffractive multifocal intraocular lens. J Cataract Refract Surg 2010; 36:1323-1329

28. Visser N, Nuijts RMMA, de Vries NE, Bauer NJC. Visual outcomes and patient satisfaction after cataract surgery with toric multifocal intraocular lens implantation. J Cataract Refract Surg 2011; 37:2034-2042

29. Bellucci R, Bauer NJC, Daya SM, Visser N, Santin G, Cargnoni M, Nuijts RMMA; for the Lisa Toric Study Group. Visual acuity and refraction with a diffractive multifocal toric intraocular lens. J Cataract Refract Surg 2013; 39:1507-1518

30. Diaz-Valle D, Arriola-Villalobos P, García-Vidal SE, SánchezPulgarín M, Borrego Sanz L, Gegúndez-Fernández JA, Benitez-del-Castillo JM. Effect of lubricating eyedrops on ocular light scattering as a measure of vision quality in patients with dry eye. J Cataract Refract Surg 2012; 38:1192-1197

31. de Vries NE, Franssen L, Webers CAB, Tahzib NG, Cheng YYY, Hendrikse F, Tjia KF, van den Berg TJTP, Nuijts RMMA. Intraocular straylight after implantation of the multifocal AcrySof ReSTOR SA60D3 diffractive intraocular lens. J Cataract Refract Surg 2008; 34:957-962

32. Ferrer-Blasco T, Montés-Micó R, Cerviño A, Alfonso JF. Light scatter and disability glare after intraocular lens implantation [letter]. Arch Ophthalmol 2009; 127:576-577. Available at:
http://archopht.jamanetwork.com/data/Journals/OPHTH/10060/ elt0409_576_577.pdf. Accessed November 19, 2014

33. Alfonso JF, Fernández-Vega L, Señaris A, Montés-Micó R. Prospective study of the Acri.LISA intraocular lens. J Cataract Refract Surg 2007; 33:1930-1935

34. Mesci C, Erbil HH, Olgun A, Yaylali SA. Visual performances with monofocal, accommodating, and multifocal intraocular lenses in patients with unilateral cataract. Am J Ophthalmol 2010; 150:609-618

35. Bellucci R. Multifocal intraocular lenses. Curr Opin Ophthalmol 2005; 16:33-37

36. de Vries NE, Nuijts RMMA. Multifocal intraocular lenses in cataract surgery: literature review of benefits and side effects. J Cataract Refract Surg 2013; 39:268-278

37. Braga-Mele R, Chang D, Dewey S, Foster G, Henderson BA, Hill W, Hoffman R, Little B, Mamalis N, Oetting T, Serafano D, Talley-Rostov A, Vasavada A, Yoo S; for the ASCRS Cataract Clinical Committee. Multifocal intraocular lenses: relative indications and contraindications for implantation. J Cataract Refract Surg 2014; 40:313-322

\section{OTHER CITED MATERIAL}

A. Carl Zeiss Meditec AG. [Online calculator]. Available at: https:// zcalc.meditec.zeiss.com/zcalc/. Accessed November 19, 2014

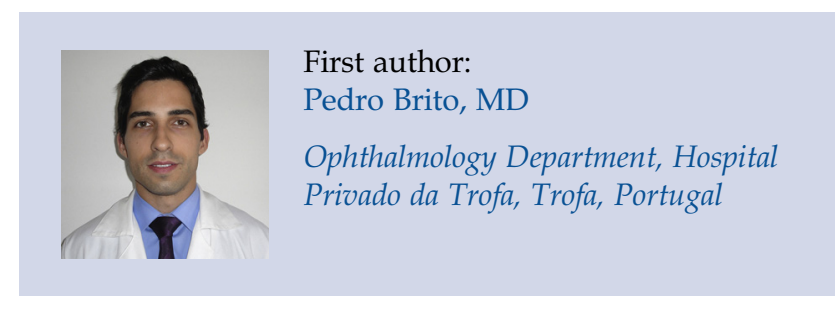

